\title{
ENERGY EFFICIENT IMPROVEMENTS TO THE ENVELOPE OF LOW-INCOME HOUSING: A CASE STUDY OF HABITAT FOR HUMANITY HOMES
}

\author{
Avani Goyal ${ }^{1}$, Ahmet Kilinc ${ }^{2}$, Minkyung Kang ${ }^{3}, \&$ Burcu Akinci $^{4}$
}

\begin{abstract}
Low-income families pay substantial portions of their total expenditure on household energy bills, making them vulnerable to rising energy costs. Habitat for Humanity houses are built for low-income families and made affordable with volunteer work and construction material donations. Hence, the trade-off between the homes' initial construction costs and their life-time energy costs must be evaluated carefully. This paper targets to support better-informed decisions that balance the affordability of certain construction materials with their potential for energy efficiency. In collaboration with Habitat for Humanity of Westchester, we created an energy simulation model of an existing low-income house and calculated the home's annual energy usage with different design alternatives for windows and walls. The resulting estimated annual energy savings are then evaluated alongside their initial investment costs, which were retrieved from RS Means standard construction cost data and quotations from industry. The results show that it is possible to reduce the energy cost of these houses without significantly increasing the construction costs through exploration of different wall and window options. While specific enclosure suggestions apply to this case-study, the utilized approach on exploring different options to identify opportunities to save energy can be used to understand impact on the lives of low-income families.
\end{abstract}

Keywords: Low-Income housing, Energy Efficiency, Cost Analysis, Residential Housing, Habitat for Humanity.

\section{INTRODUCTION}

It has been reported that low-income households face nearly twice of the energy cost burden than that of an average US household (HHS 2009). The number of low-income households spending over $10 \%$ of their income on home energy increased from 4.4 million in 2001 to 5.7 million in 2009 (HHS 2009). Policy makers allocate significant resources to support them by improving the energy performance of their homes and by funding energy-use subsidies (EIA 2015).

Habitat for Humanity is a non-profit organization dedicated to constructing affordable, low-income homes. In 2015, Habitat served 1.8 million individuals with new home construction, repair, or rehabilitation worldwide (Habitat for Humanity

1 Graduate Student, Civil and Environmental Engineering, Carnegie Mellon University, PA, USA, avanig@andrew.cmu.edu

2 Undergraduate Student, Mechanical Engineering, Carnegie Mellon University, aykilinc@andrew.cmu.edu

3 Graduate Student, Civil and Environmental Engineering, Carnegie Mellon University, PA, USA, mkang2@andrew.cmu.edu

4 Paul Christiano Professor, Civil and Environmental Engineering, Carnegie Mellon University, Pittsburgh, PA, USA, bakinci@cmu.edu 
International, 2015). Since the Habitat for Humanity primarily utilizes volunteer labour and donated building materials and appliances, the homes built by the organization can be prone to lower energy efficiencies. Often, donors of construction materials cannot compare the impact of their donations on the energy usage of the homes. Therefore, to support better informed decisions on the part of donors and builders and truly provide more affordable homes for the low-income families, one needs to take into account the financial implications of energy efficient improvements, balancing the cost of installing the improvements with the energy savings they will likely yield.

Myriad studies were initiated to improve the energy performance of buildings with different design alternatives (e.g., Ma et al. 2012; Al-Homoud 2001). However, limited attention has been paid to low-income households. Past studies on energy efficient lowincome housing include energy baselines for low-income homes (Haberl et al. 199) and energy savings potentials due to occupant behavior changes (Langevin et al. 2013) or retrofits (Parker et al. 1998). While these studies improved understanding of energy usage patterns, few to none considered the financial implications of the energy efficient improvements. Studies that consider both initial construction costs and life-cycle energy savings, on the other hand, paid little attention to low-income houses (Pikas et al. 2014).

The overarching goal of the research study described in this paper aims at enabling consideration of different design alternatives to support consideration of not only the initial construction cost, but also long term energy cost. Only through such analyses, it would be possible to fully assess the practical value of using energy efficient materials in low-income houses. In this paper, we specifically focus on doing such analyses for a two-household residential unit designed by Habitat for Humanity of Westchester as an example of low-income homes. We performed parametric energy simulations several design alternatives including the building's exterior walls and windows, given that exterior enclosure significantly impacts the energy utilization in a home. The home's annual energy consumption with these alternatives was investigated to identify potential energy saving solutions. Finally, the initial construction cost and the estimated energy savings of the design alternatives were compared to identify estimated payback for any increase in initial investment costs.

\section{CASE STUDY OVERVIEW}

Figure 1 shows the 2-story, multi-family building in New York, USA used in the study. The building is designed using one of the templates used by Habitat for Humanity of Westchester to efficiently construct affordable homes. The home is split into two mirroring halves by a central wall, each made to house a single family with a total of two families residing in the entire building. The floor area of the building is $187.76 \mathrm{~m}^{2}$. The building uses Structural Insulated Panels (SIP) that is composed of 5" (1.524m), expanded polystyrene (EPS) as insulation layer and 1/4" $(0.762 \mathrm{~m})$ Oriented Strand Board (OSB) on either sides of the foam insulation. The windows used are single pane with metal framing.

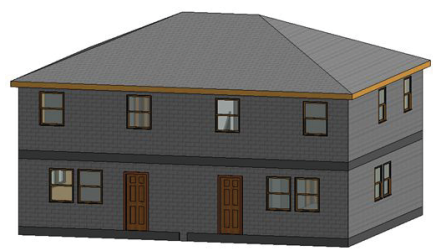

Figure 1: 3D view of the Building Information Model for energy simulations 


\section{BASELINE MODEL INPUTS AND ANALYSIS}

\subsection{DesignBuilder Inputs and Assumptions}

A simulation model was created as per the provided plans with some assumptions for information necessary for modeling that were not given in the plans as below. For Heating, Ventilation and Air Conditioning (HVAC), the standard ASHRAE template for Packaged Terminal Air-Conditioner (PTAC) is selected with heating and cooling set points as $20^{\circ} \mathrm{C}$ and $26^{\circ} \mathrm{C}$ respectively and infiltration rate as $0.3 \mathrm{AC} /$ hour. Internal loads include the energy consumption associated with occupancy, equipment and lighting as demonstrated in Table 1. The occupancy schedule template for a standard residential case is selected and the lighting schedule is modified from the base ASHRAE template to be more aligned with the occupancy schedule pattern in the case study house.

Table 1: Assumptions made for internal Loads

\begin{tabular}{ccc}
\hline Input & Data & Explanation \\
\hline $\begin{array}{c}\text { Occupancy } \\
\text { Level }\end{array}$ & $\begin{array}{c}0.04 \\
\text { persons } / \mathrm{m}^{2}\end{array}$ & $\begin{array}{c}\text { Prior information that there are approximately 8 people in total } \\
\text { for 2 units, which is 0.04 person } / \mathrm{m}^{\mathrm{s}}(=8 / 200)\end{array}$ \\
\hline Miscellaneous & $3 \mathrm{~W} / \mathrm{m}^{2}$ & Major appliances as per ASHRAE Fundamentals Handbook \\
\hline $\begin{array}{c}\text { Lighting } \\
\text { Power Density }\end{array}$ & $6 \mathrm{~W} / \mathrm{m} 2$ & $\begin{array}{c}\text { Maximum } 8 \mathrm{~W} / \mathrm{m}^{2}(\text { ASHRAE Standard } 90.1-2004) \text {. For the target } \\
\text { of } 300 \mathrm{lux}, 2 \mathrm{~W} / \mathrm{m}^{2}-100 \text { lux is set to get } 6 \mathrm{~W} / \mathrm{m}^{2} \text { overall }\end{array}$ \\
\hline
\end{tabular}

\subsection{Baseline Model Performance}

Under the weather condition of Typical Meteorological Year 3 (TMY3) data for White Plains - Westchester county location, the performance of the baseline model parameters is shown in Table 2. For the cost, we used the most recent energy utility costs published by the New York State Energy Research and Development Authority on February $10^{\text {th }}$, 2016 , which are $\$ 0.186 / \mathrm{kWh}$ for the electricity and $\$ 0.04 / \mathrm{kWh}$ for gas.

Table 2: Energy and utility cost result of the baseline model simulation

\begin{tabular}{cc}
\hline Input & Data \\
\hline Total annual energy consumption & $18,426.3 \mathrm{kWh}$ \\
\hline Total energy use intensity (EUI) & $90.6 \mathrm{kWh} / \mathrm{m}^{2}$ \\
\hline Annual utility cost & $\$ 2605.12$ \\
\hline
\end{tabular}

In the baseline energy simulations, electricity contributes to around $68 \%$ of the total energy consumption, while gas contributes to around $32 \%$. This corresponds to the fact that our focus of study is New York, which is in the cold climate zone, where heating is dominant energy consumer. The entire gas consumption is attributed to the heating load, while the majority of the electricity consumption is attributed to the lighting and equipment load.. As seen in Figure 2, the heating energy consumption is observed to increase considerably during the winter months due to the heating load. 


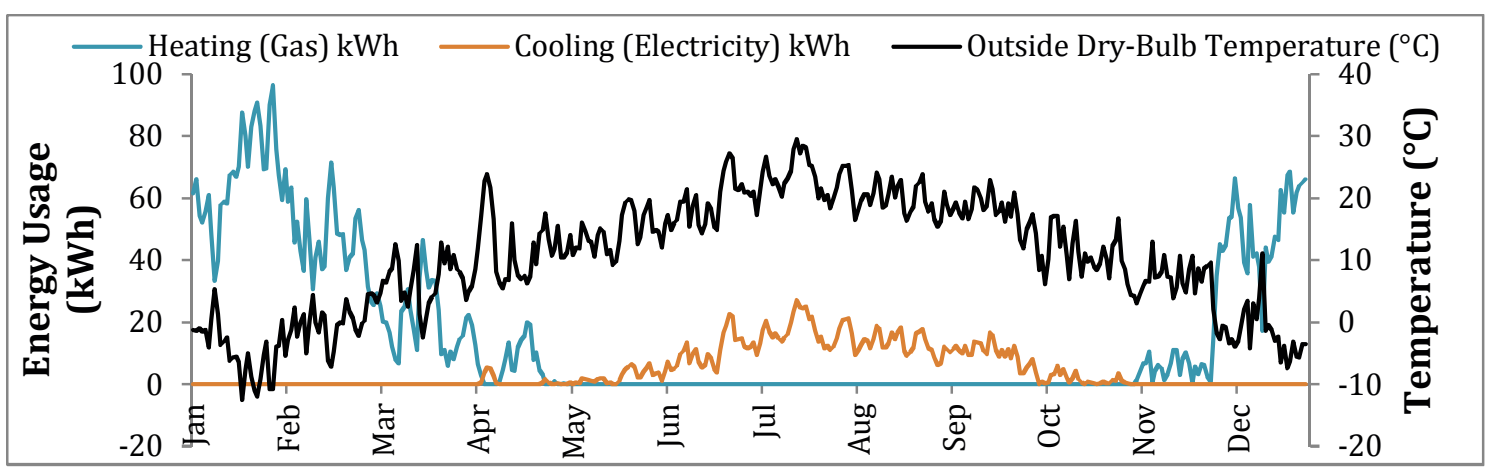

Figure 2: Daily heating and cooling energy with the average outside temperature

Even though the trends of outdoor temperature and heating and cooling load correspond to each other, the overall cooling load is observed to be much lesser than the heating load. This can be attributed to the difference in the amount of heating and cooling degree-days. The heating degree days (HDD) and cooling degree days (CDD) are 1544 and 4496 days respectively for 2015 (NYSERDA 2016), which explains that the cooling requirement is one-third of the heating requirement.

\section{PARAMETRIC STUDY FOR BUILDING ENVELOPE}

Based on the baseline model analysis, the heating load primarily dictates the energy consumption for the case study house. Therefore, we can achieve energy savings by optimizing the thermal envelope components such as the exterior walls and windows through parametric analysis.

\subsection{Walls}

The initial analysis considered various wall types that are commonly used in the northeast region of the U.S. (New York City, 2016) in addition to Insulated Concrete Form (ICF), concrete masonry and brick wall that are compared to the Structural Insulated Panel (SIP) walls of baseline model. Most of them could be categorized into one of the wall configurations described in Table 3 based on their thermal properties. All the wall types are simulated keeping the insulation type constant as EPS foam. The thickness of the overall assembly is kept similar to the baseline of around 6" for a fair comparison except for ICF that are usually thicker.

Table 3: Description of wall types

\begin{tabular}{cc}
\hline Wall Type & Configuration \\
\hline SIP & Oriented Strand Board (OSB) + Insulation + OSB \\
\hline ICF & ypsum board + insulation + reinforced concrete + insulation + gypsum plasterboard \\
\hline CMU & Concrete + gypsum board + insulation + gypsum board + plasterboard \\
\hline Brick Wall & Brick + insulation + gypsum board + plasterboard \\
\hline
\end{tabular}

Table 4 below shows that the ICF wall provides the largest energy cost savings. However, the second most efficient option of SIP wall reduces the material cost by onethird against marginal utility cost savings with the ICF option. Hence, due to the higher 
price and large assembly thickness of ICF wall, SIP is considered to be a more optimal solution for low-income housing.

Table 4: Energy Simulation Results of Wall Alternatives

\begin{tabular}{ccccc}
\hline Wall Type & $\begin{array}{c}\text { U-value } \\
\left(\mathbf{W} / \mathbf{m}^{2}-\mathrm{K}\right)\end{array}$ & $\begin{array}{c}\text { Energy Consumption } \\
\mathbf{( k W h / y r )}\end{array}$ & $\begin{array}{c}\text { Utility Cost } \\
\mathbf{( \$ / y r )}\end{array}$ & $\begin{array}{c}\text { Material Cost } \\
\mathbf{( \$ )}\end{array}$ \\
\hline SIP & 0.29 & 18,270 & 2605 & 4,890 \\
\hline ICF & 0.277 & 16,919 & 2421 & 12,223 \\
\hline CMU & 0.90 & 25,162 & 2909 & 8,694 \\
\hline Brick & 0.901 & 25,648 & 2923 & 15,775 \\
\hline
\end{tabular}
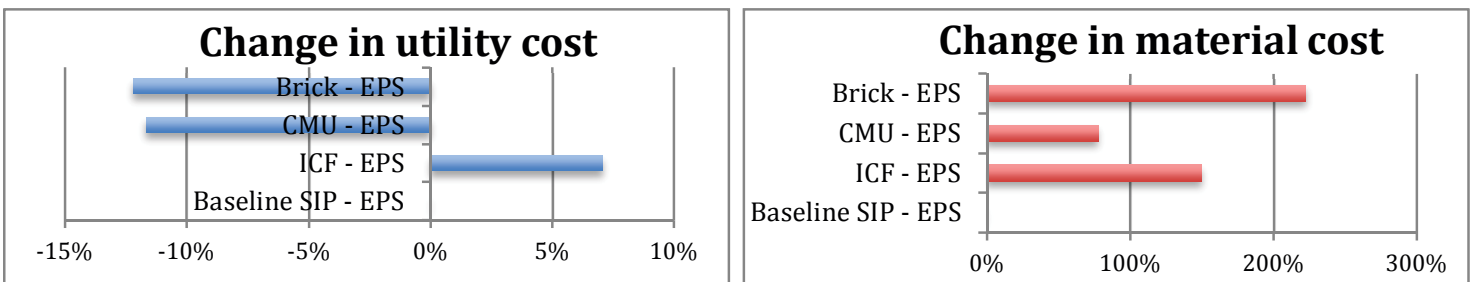

Figure 3: Change in Utility (left) and Material Cost (right) of Wall Alternatives

SIP as exterior wall option is further analyzed using different insulation materials, such as extruded polystyrene (XPS), polyicocyanurate (PIR) and glass fibre (GF) board as described in Table 5 below. SIP with PIR insulation offers the highest energy cost savings of $3.7 \%$, but with large material investment. Whereas, SIP with glass fibre decreases the material cost along with the utility cost savings, and hence, can be more suitable for lowincome housing.

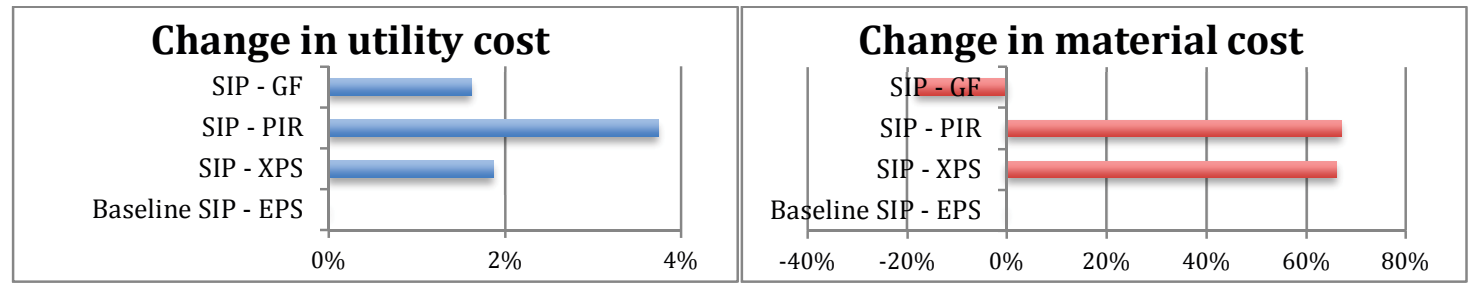

Figure 4: Change in Utility (left) and Material Cost (right) of SIP Wall Alternatives

Table 5: Energy Simulation Results of SIP Wall Alternatives

\begin{tabular}{ccccc}
\hline Wall Type & $\begin{array}{c}\text { U-value } \\
\left(\mathrm{W} / \mathrm{m}^{2}-\mathrm{K}\right)\end{array}$ & $\begin{array}{c}\text { Energy } \\
\text { Consumption } \\
(\mathrm{kWh} / \mathrm{yr})\end{array}$ & $\begin{array}{c}\text { Utility Cost } \\
(\mathbf{\$} / \mathrm{yr})\end{array}$ & Material Cost $\mathbf{( \$ )}$ \\
\hline SIP-EPS & 0.29 & 18,270 & 2,605 & 4,889 \\
\hline SIP-XPS & 0.22 & 17,380 & 2,556 & 8,123 \\
\hline SIP-PIR & 0.14 & 16,046 & 2,508 & 8,165 \\
\hline SIP-GF & 0.26 & 17,495 & 2,563 & 4,007 \\
\hline
\end{tabular}


Energy Efficient Improvements to the Envelope of Low-Income Housing: A Case Study of Habitat for Humanity Homes

\subsection{Windows}

In this study, three sets of double-pane windows are chosen for analysis since they showed great potential to balance initial investment costs with overall energy savings. We also chose two sets of Low-E (low emissivity) windows specifically to analyze their performance under cold climate conditions. In addition, two triple-pane windows are also studied to explore areas for further improved efficiency.

Table 6: U-value, SGHC, \& VLT of Window Alternatives

\begin{tabular}{cccc}
\hline Design alternative & U-value $(\mathrm{W} / \mathrm{m} 2-\mathrm{K})$ & SHGC & VLT \\
\hline Triple Low-E Clear & 1.55 & 0.47 & 0.66 \\
\hline PPG Double SolarBan 70XL & 1.63 & 0.27 & 0.64 \\
\hline Triple Low-E Film Bronze & 1.74 & 0.20 & 0.22 \\
\hline Double Low-E Clear Cold Climate & 1.96 & 0.67 & 0.72 \\
\hline Double Low-E Clear & 1.99 & 0.73 & 0.74 \\
\hline Baseline & 3.12 & 0.4 & 0.56 \\
\hline
\end{tabular}

Table 7: Annual Energy Consumption and Cost analysis for glazing alternatives

\begin{tabular}{cccrc}
\hline Design Alternative & $\begin{array}{c}\text { Annual Electricity } \\
\text { Consumption }(\mathrm{kWh})\end{array}$ & $\begin{array}{c}\text { Annual Fuel } \\
\text { Consumption } \\
(\mathbf{k W h})\end{array}$ & $\begin{array}{c}\text { Total Annual } \\
\text { Utility Cost }(\mathbf{})\end{array}$ & $\begin{array}{c}\Delta \text { Material } \\
\text { Cost From } \\
\text { Baseline(\$) }\end{array}$ \\
\hline Triple Low-E Clear & 12,559 & 4,290 & 2,527 & 2,490 \\
\hline PPG Double SolarBan 70XL & 12,330 & 5,206 & 2,525 & 1,460 \\
\hline Triple Low-E Film Bronze & 12,261 & 5,600 & 2,529 & 3,436 \\
\hline Double Low-E Clear Cold Climate & 12,873 & 3,674 & 2,558 & 780 \\
\hline Double Low-E Clear & 12,995 & 3,417 & 2,569 & 723 \\
\hline Baseline & 12,454 & 5,972 & 2,582 & 0 \\
\hline
\end{tabular}

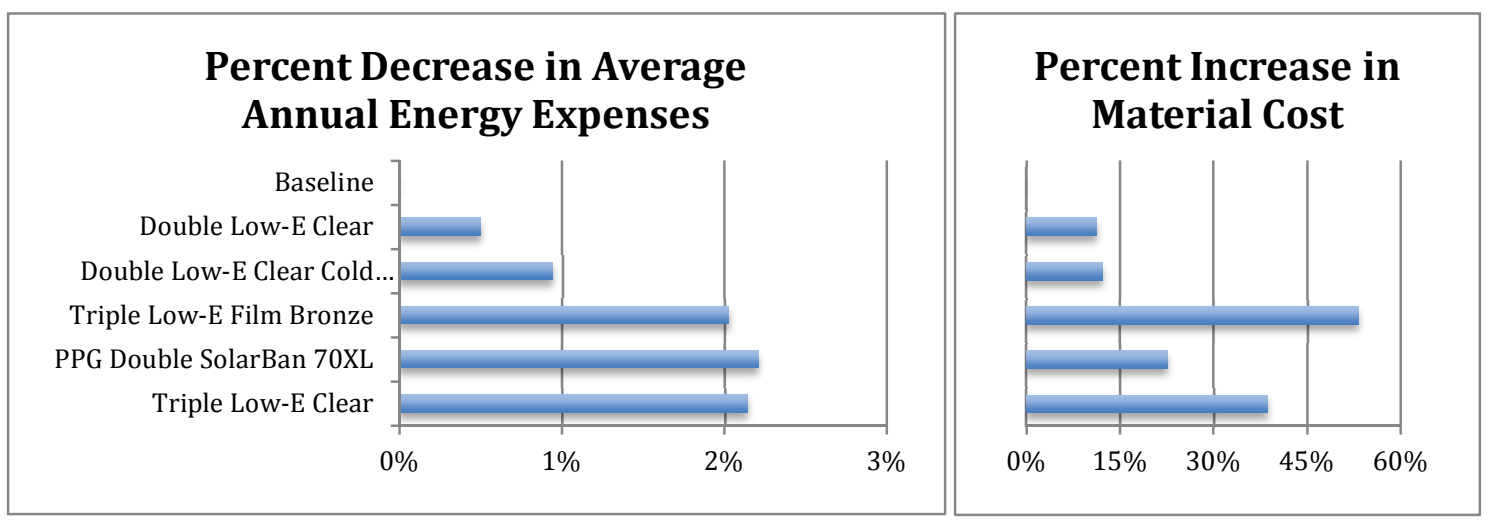

Figure 5: Change in Utility (left) and material cost (right) of glazing alternatives 
The PPG Double SolarBan 70XL option offers the highest savings in average annual energy expenses. While both triple pane alternatives provide similar savings for average annual energy expense, they both require a far greater increase in material cost. The material costs of each are obtained from market research of local manufacturers and distributors. The U-value of a thermal envelope component is a common parameter to estimate the energy consumption. However, unlike walls, the windows simulation results are not directly correlated and hence SHGC values are also analyzed to understand the results. For instance, comparing first two options, the Triple Low-E alternative has a lower U-value and higher SHGC than does the SolarBan 70XL alternative; decreasing the heating load in winters and hence shows higher gas savings while showing higher electricity consumption. However, the overall energy cost savings are greater for the PPG Double SolarBan 70XL alternative as it creates an increase in electricity savings that cost considerably more than natural gas in the NY region.

\section{DisCUSSIONS AND CONCLUSIONS}

This study explores potential energy costs savings for low-income homes that can be achieved through investments on construction materials of walls and windows. A parametric study was conducted using the DesignBuilder modeling software for an actual low-income family house design of Habitat for Humanity of Westchester.

The results show that the windows and walls can improve annual energy utility costs by about 9\% through the application of ICF walls and PPG Double-Pane SolarBan 70XL windows. However, since the ICF walls are thicker and reduce the available floor space, this case study finds SIP walls to be more suitable for this situation. SIP walls with PIR insulation have the greatest energy cost savings of around $4 \%$. The results of the walls' parametric study confirm that the energy consumption is directly correlated to U-value and therefore can be used as a guideline for energy efficient house design.

The windows parametric study suggests that, in addition to the U-value, SHGC value is also a significant factor contributing to the overall energy consumption in the case study house. This is because high SHGC values allow for increased solar heat gain, reducing overall heating demand. Another interesting result is that the window option with the least energy consumption differs from the option with least annual energy cost. This discrepancy is due to the significant difference in fuel and electricity costs. Therefore, this study emphasizes that one needs to consider the different utilized fuel types and their unit costs before establishing the design.

There are limitations in this study that are mainly due to the assumptions and challenges inherent in the cost extraction process. First, the cost extracted from the RS Means data can be different from actual market prices. For instance, the SIP panel costs in this study are calculated by summing up the cost of each layer; meanwhile, this sum can be different from the actual assembly cost. Also, the limited material options in the RS Means resulted in potential inaccuracies in the cost information. For instance, we assumed the concrete blocks have a fixed R-value as in the RS Means database while there can be a wide range of variation in thermal properties and construction costs within concrete materials. However, even with these potential errors in material cost information as well as with the specificity of enclosure suggestions to this particular case study, the utilized approach on exploring different options to identify energy saving opportunities suggested in this study can be utilized for understanding its impact on the lives of low-income families. 


\section{ACKNOWLEDGMENTS}

The authors would like to acknowledge the design information and feedback provided by the Board of Directors and builders of Habitat for Humanity of Westchester during this research study. Any opinions, findings, conclusions or suggestions presented in this paper are those of authors and do not necessarily reflect the views of the Habitat for Humanity.

\section{REFERENCES}

Al-Homoud, M. S. (2001). Computer-aided building energy analysis techniques. Building and Environment, 36(4), 421-433.

ASHRAE, A. S. (2004). Standard 90.1-2004, Energy standard for buildings except low rise residential buildings. American Society of Heating, Refrigerating and AirConditioning Engineers, Inc.

EIA (US Energy Information Administration). (2015). Direct federal financial interventions and subsidies in energy in fiscal year 2013.

Langevin, J., Gurian, P. L., \& Wen, J. (2013). Reducing energy consumption in lowincome public housing: Interviewing residents about energy behaviors. Applied Energy, 102, 1358-1370.

Haberl, J. S., Bou-Saada, T., Soebarto, V., \& Reddy, A. (1998). Use of Calibrated Simulation for the Evaluation of Residential Energy Conservation Options of Two Habitat for Humanity Houses in Houston, Texas. In The Eleventh Symposium on Improving Building Systems in Hot and Humid Climates (pp. 1-2).

HHS (US Department of Health and Human Services) (2011). LIHEAP Home energy notebook for fiscal year 2009.

Ma, Z., Cooper, P., Daly, D., \& Ledo, L. (2012). Existing building retrofits: Methodology and state-of-the-art. Energy and Buildings, 55, 889-902.

NYSERDA

Accessible: https://www.nyserda.ny.gov/About/Publications/EA-Reports-and-Studies/WeatherData/Monthly-Cooling-and-Heating-Degree-Day-Data

Parker, D., Sherwin, J., \& Floyd, D. (1998). "Measured Energy Savings From Retrofits Installed in Low-Income Housing In a Hot and Humid Climate", 11th Symposium on Improving Building Systems in Hot and Humid Climates, Ft. Worth, Texas.

Pikas, E., Thalfeldt, M., \& Kurnitski, J. (2014). Cost optimal and nearly zero energy building solutions for office buildings. Energy and Buildings, 74, 30-42.

City of New York. (2016). "2014 Construction Codes", Accessible: https://www1.nyc.gov/site/buildings/codes/nyc-code.page

Habitat for Humanity International (2015) “Annual report FY2015" http://www.habitat.org/sites/default/files/annual-report-2015.pdf 